\title{
Which Helps to Become a Better EFL Writer: Creative Tasks or Communicative Tasks?
}

\author{
Roya Khoii, Elham Amin \\ Islamic Azad University \\ North Tehran Branch
}

\begin{abstract}
Given the importance of creativity in education and language teaching, this study explored the effects of using creative tasks, such as writing name poems, short stories, TV adverts, acrostic poems, etc., on the improvement of foreign language learners' writing ability. The tasks employed in this study enjoyed two distinctive features: the use of multiple experiences and constraints. A secondary goal here was to illustrate how instances of creative language play can provide learners with opportunities to practice a variety of linguistic forms that are usually ignored in EFL classrooms. For this purpose, the performance of 16 intermediate level adult female students in the experimental group (performing creative tasks) was compared to their counterparts in the control group (performing communicative tasks) over a period of 4 weeks. The results indicated that the experimental group had significantly outperformed the control group in terms of EFL writing. They also showed that engaging in creative play tasks with formal and semantic constraints encourages learners to explore, expand, and transform their language output at lexical and syntactic levels.
\end{abstract}

\section{Introduction}

Over the past decades, various sub-fields of linguistics have shown considerable interest in the notion of creativity. It is claimed that creativity is at the very core of language itself; it is the essential property of language which, according to Chomsky, "provides the means for expressing indefinitely many thoughts and for reacting appropriately in an indefinite range of new situations" [1].

Language creativity has been defined as the playful use of language to make new meanings [2]. Language play includes a wide variety of activities, as any communication takes place through manipulations of linguistic form and meaning [3]. Many researchers have suggested the inclusion of form and semantic oriented creative tasks in language teaching and emphasized the importance of developing creative competence in L2 learners [4] and [5]. Despite increasing interest among SLA researchers in the value of creative tasks or language play in language learning, few empirical studies have examined how creative writing tasks and language play might contribute to language development and the improvement of learners' writing skill.

The playful use of language encourages learners to combine a broader range of lexical items and syntactic constructions in order to produce new meanings. Engagement in language play can facilitate the use of more complex and varied linguistic forms; opportunities learners do not necessarily have when they use communicative writing tasks in classrooms [3]. On the other hand, communicative and traditional writing tasks still play an important role in language learning/teaching. However, the successful completion of activities in communicative writing tasks needs a limited communicative repertoire. Learners do not need to test the boundaries of their linguistic knowledge to do what is expected of them. Tin [2] argues that in communicative writing tasks language is used as a tool just for communication not for making new meaning. She believes that promoting a creative desire and the need for learners to say something new is as important as the need to communicate known meanings.

Among several conditions that can help learners to establish a creative desire and improve their writing ability, the present study discusses two that could be set up to promote creativity in writing tasks: multiple experiences and constraints. Research suggests a connection between creativity and multiple experiences [6]. Being exposed to different experiences can lead to cognitive flexibility and creativity. It can generate opportunities for creativity, allowing one to see new perspectives of familiar things. Linguistic competence also develops through experience: the more varied experiences a learner has with the L2, the more that person will develop a strong and broad communicative repertoire [3].

The other prevalent element in creative writing tasks is constraints. The constraints observed in creative writing tasks are different from the kind of limitations found in controlled communicative writing tasks. The constraints found in communicative writing tasks often prompt learners to retrieve what they already know to construct known meaning while limiting their search for 
riskier, unknown areas. In contrast, a constraint that leads to creativity prompts learners to search among the unknown to make new meaning, while limiting their search through what they already know [2]. The constraints used in the present study were of two kinds: formal and semantic.

Learners invest more in their language with rich uses of language at both syntactic and lexical levels in creative writing tasks as compared with their performance in communicative writing tasks [3 and 7]. In fact, the formal and semantic constraints present in creative writing tasks require L2 learners to develop new syntactic structures, combining known familiar utterances in unfamiliar ways in order to construct new meanings [8].

\section{Theoretical Framework}

The development of one's skills in creative writing relies heavily on providing opportunities to practice them. Although the word training often replaces the word practice, they have completely different meanings, and the distinction is crucial. Having clear goals and reaching those goals are the ultimate point in training for something although the process one follows to attain those goals is a secondary consideration [9].

In traditional language learning the training of language skills, particularly vocabulary and grammar, is of great importance. Specific skills are trained within clearly defined frameworks which imply focusing on distinctly defined, short term, testable goals. Practicing is substantially different from training since in practicing the nature of the practice and transforming the practitioner - whether they reach a goal or not - is important. In fact, practicing involves a longer and subtler process. Lutzker [9] believes that creative writing can help mastering a foreign language if it is considered as a long-term process of developing imaginative, perceptual, and expressive capabilities. Chase [10] also believes that the writing ability plays an important role in students' learning. Being able to write is a fundamental element for success in all academic disciplines, and it is a lifelong skill [11].

Creative writing increases improvement in language capabilities because the degree of affective and cognitive engagement in this kind of writing is much higher than in those activities including specific language-learning goals [12]. Moreover, creative writing can develop language at all levels: grammar, vocabulary, phonology and discourse. "As learners manipulate the language in interesting and demanding ways in their attempt to express uniquely personal meanings, they necessarily engage with the language at a deeper level of processing than with expository texts" [12].

Creativity in writing tasks can be enhanced through multiple experiences and constraints.
According to Leung et al. [6], multicultural exposure destabilizes routinized responses to the environment since it exposes people to a range of behavioral and cognitive scripts for situations. These new ideas and scripts can be the inputs for creativity because the more new ideas people have, the more likely they would come up with new combinations.

Another condition needed to facilitate creativity in writing tasks is constraints. Joyce [13] defines constraints as any limitation on freedom and choice such as rules, boundaries, and scarcity. Constraints are two sided: while one element of the constraint inhibits the search in particular parts of the problem space, the other element promotes the search in other areas of the problem space [14]. Therefore, the constraints desirable for creativity direct the search for novel solutions and limit the search among the known.

Tin [8] believes that using language to make new meaning (in creative writing tasks) facilitates language learning and helps learners to stretch and destabilize their language. She asserts that the need to construct new meanings prevents the cognitive fixation tendency by making learners search for less accessible words and phrases and combine familiar utterances in unfamiliar ways, which lead to developing complex grammar.

Being able to express ourselves creatively is a highly individual process thoroughly placed in our inner imaginative and emotional life [9]. At the same time, it demands heightened understanding and awareness of the world around us. When people are provided with opportunities to become engaged in artistic processes of creative writing, what they might learn about themselves and the world goes behind what is generally offered by most conventional schooling.

In recent years, the linguistic approach to creativity has received increasing attention among researchers in the field of applied linguistics [15]. From a linguistic perspective, creativity is connected with language play, which is defined as the expression of the speaker's or writer's creativity in "deliberately, consciously choosing to violate normal expectancies of language use by playing off different varieties against one another, for the sheer purpose of enjoyment and entertainment" [16].

Creative language use helps students to look at utterances "not just as potential objects of analysis but as potential objects of language play" [5]. Language play is natural and important in L2 learning and describes language play both at formal and semantic levels [4]. At the formal level, language users play with sounds, words, and grammatical structures and, at the semantic level, they play with units of meaning, combining them in unusual ways to create new meanings.

Recently, creativity research has widened its scope and today it is more of "an interdisciplinary 
effort than ever before" [17]. Although there is still no unanimously accepted definition for creativity in different approaches and disciplines, researchers suggest that it is closely related to novelty, originality, and divergent thinking [18].

\section{Methodology}

The research question, instruments, participants, and procedure are explained in this section.

\subsection{Research Questions}

This study was conducted to provide an answer to the following question:

To what extent does the employment of creative versus communicative tasks affect the writing ability of EFL learners?

\subsection{Instruments}

The following instruments were used to collect the required data for this research:

1. The Preliminary English Test (PET) from Cambridge ESOL exams was used to determine the homogeneity of the participants in terms of English proficiency before the treatment. This test consists of four parts: Listening ( 25 items), writing (15 items and two texts, a short letter and a descriptive writing), Reading Comprehension (35 items), and Speaking (an interview).

2. A descriptive writing pretest on a topic from the students' textbook was used to ensure their homogeneity regarding this skill.

3. A composition writing posttest was administered to both groups to examine the effects of the treatment at the end of the study.

4. The Cambridge ESOL common scale was used by two raters to score the pretest and posttest essays. Accordingly, the scripts were rated regarding four aspects of writing: content, communicative achievement, organization, and language.

\subsection{Participants}

The pool of participants consisted of 32 female Iranian intermediate level learners between 19 and 30 years old at an English Institute in Tehran. They were selected from two intact classes which were randomly assigned to one experimental and one control groups. All the participants had a ten-month experience of studying English, had already studied Total English book (Starter, Elementary, and PreIntermediate), and had passed the written final tests held every semester at the Institute. However, to further ensure the homogeneity of the two groups, a standard Cambridge ESOL PET test was administered, and eight students who proved to be outliers were removed from the study. The remaining 32 students studied Total English book (Intermediate), units one and two, in the course of 1 semester (16 sessions during 4 weeks).

\subsection{Design}

A quasi-experimental pretest-posttest nonequivalent-groups design was utilized to conduct this study since the experimental and control groups were such naturally assembled groups as intact classes. The independent variables were creative and communicative writing tasks, and the dependent variable was the writing ability of the participants. The experimental group performed creative writing tasks, whereas the control group worked on communicative writing tasks. Finally, a descriptive writing posttest was administered to both groups to examine the effects of the treatment.

\section{Procedure}

In order to carry out this study, the researchers followed the procedure detailed below:

\subsection{Administering the Homogeneity Test}

The Preliminary English Test (PET) from Cambridge ESOL exams was used in this study to determine the homogeneity of the participants before the treatment. Forty intermediate students were initially tested on their English proficiency through the Cambridge PET exam. Eight students proved to be outliers and were removed from the study. The remaining 32 students, who had scored within one standard deviation above and below the mean, were selected for the study. Then they were randomly assigned to two groups of 16 students, one as the control group and the other as the experimental group.

\subsection{Administering the Writing Pretest}

To ensure the homogeneity of the participants in terms of their writing ability, a writing pretest was administered to both groups. The students were asked to write a descriptive essay between 70-100 words on a given topic chosen from their course book before the treatment began. The Cambridge ESOL common scale was next used to score the students' pretest papers. Then the papers were assessed analytically by the researchers. The students in this study were given scores from 0 to 10 .

Further, the inter-rater reliability of the two sets of scores on the writing pretest was calculated using 
the Pearson Product-Moment Formula. Then the total writing score of each participant was computed by averaging the two raters' scores. Finally, the mean scores of the two groups on the test were compared using a t-test.

\subsection{Treatment}

The educational program of the Institute lasted for 20 sessions in the course of 1 semester (4 weeks). In order to control the teacher variable, the two groups were taught by the same teacher (one of the researchers). After administering the homogenizing and writing pretest in the first two sessions of the class successively, the treatment began and continued for sixteen sessions, each session for 40 minutes. The experimental group performed creative writing tasks, while the control group performed communicative writing tasks. The creative writing tasks were of different types, for instance, the students were asked to write very simple name poems, short stories, TV adverts, acrostic poems, newspaper articles and headlines, and travel guide brochures.

Among the several conditions that can help to establish a creative zone and a creative desire, the researchers chose two that could promote creativity in language learning tasks: multiple experiences and constraints. The creative writing tasks employed in the experimental group exposed learners to different experiences, generated opportunities for creativity, and allowed them to develop new perspectives of familiar things. These new ideas and concepts were the inputs for creative expansion processes because the more new ideas the students had, the more likely they were to develop novel combinations. In fact, it was tried to enhance the students' creativity by exposing them to multiple experiences which facilitated combinational creativity where new ideas were produced by combining ideas from different remote disciplines. In doing so, the students were required to do some mini research projects related to the topic they were supposed to write about prior to performing most tasks.

The second condition which was imposed to facilitate creativity was constraint. As mentioned before, a constraint is a limitation on freedom and choice such as rules, boundaries, and scarcity [13]. It was also stated that one element of the constraint prevents searching in particular areas of the problem space, while the other promotes searching in other parts of the problem space [14]. Hence, in order to act creatively, the students had to search for novel combinations and distance themselves from the known. Boden [19] claims that the principled, imaginative use of constraints is important for creativity. Therefore, the types of constraints imposed, as well as the manner or timing of constraint imposition were of great importance in this study. Finding new constraints to work with has been one of the features of many creative works. The constraints imposed in the creative writing tasks of this study were mostly of two kinds: formal and semantic. Formal constraints are related to the form or structure of the utterance whereas semantic constraints are the ones related to the meaning. In terms of timing, the teacher avoided revealing the constraints at the beginning of the tasks as the presence of a clearly defined goal at this stage was likely to activate known past experiences instead of broadening the learners' language.

The creative writing tasks employed in the experimental group were based on the general approach of creative writing. In the general approach, there are two phases in a creative task: idea generation and idea exploration [20]. In the idea-generation phase, the students in the experimental group were presented with an illdefined problem and were asked to generate ideas or pre- inventive forms without knowing the final result or the goal of the task. Pre-inventive forms are the words and sentences generated by the students while they do not know what meanings and functions they would serve or what they would be used for.

In the idea-exploration phase, after the production of words and sentences by the students, the teacher introduced a new constraint, and the learners were pushed to interpret the previously generated pre-inventive forms in accordance with the new constraint. The new constraints helped the students to use the ideas generated to construct some unknown meaning about the topic.

The students in the experimental group worked in pairs in order to accomplish the tasks by interacting and exchanging opinions during the whole project with the teacher supervising and observing their negotiations and providing help when necessary. However, she avoided interrupting the students to correct them unless communication was impeded. At the end of each session, the students read their paragraphs to the class.

During the treatment, it was tried to create a balance between the amounts of writing practice in the two groups. The students in the control group performed communicative writing tasks over 16 sessions, each session for 40 minutes. Although the element of constraint was prevalent in the communicative writing tasks, it differed from the kind of limitations found in creative writing tasks. The limitations found in the communicative writing tasks prompted the control group to review what they knew to express known meaning while limiting their search for riskier, unknown areas. For instance, by reordering the words of a line or using a given sentence structure, they tried to write new patterns or to express in written form what they had seen in a picture or been given as known information. They 
were also required to find mistakes in the given texts or match descriptions to paragraphs.

The students in the control group also worked in pairs in order to accomplish the tasks by interplaying and exchanging ideas. The time allocated to completing each task differed based on the task itself. After finishing the task, the students were given the correct form of the task to help them check their choices and pay attention to the targeted features in their groups while the teacher provided the necessary help and feedback. Each student in the control group was also asked to write an essay on their own on a topic related to the theme of their text book and lesson. After drafting, the students provided feedback to each other's work with the teacher monitoring their negotiations. With the help of the comments they received from their pair and the teacher, they were asked to revise and edit their work at home. The final drafts were written at home and handed to the teacher the next session for evaluation.

In fact, the only difference between the two groups in this study was the type of tasks used in each group. As mentioned before, the experimental group received creative tasks whereas the control group received communicative tasks.

\subsection{Administering the Writing Posttest}

To measure the effects of the treatment, the participants in both groups took a descriptive essay writing posttest in the $20^{\text {th }}$ session of the course. The same raters then scored the papers analytically. The inter-rater reliabilities of the two sets of scores for each group on the writing posttest were calculated through the Pearson Product-Moment Formula. Then the total writing score of each participant was computed through averaging the two raters' scores. Finally, the means of both groups were compared through running a t-test.

\section{Data Analysis}

Several statistical analyses were conducted in order to find a convenient answer to the research question. The results are reported below.

\subsection{Homogeneity Test Results}

The Preliminary English Test (PET) from Cambridge ESOL exams was used in this study to determine the homogeneity of the participants before the treatment. Forty intermediate students took the PET test. All those who scored between one standard deviation above and below the mean were selected and randomly assigned to two groups. The descriptive statistics of the two groups are given in Table 1.
Table 1. Descriptive statistics of the two groups on the PET

\begin{tabular}{|lccccc|c|}
\hline & & \multicolumn{3}{c}{ Std } & \multicolumn{3}{c|}{ Skewness } \\
& N & Mean & Error. Mean & SD & Statistic & Std. Error \\
\hline C & 16 & 60.84 & 1.68 & 6.73 & 0.448 & 0.564 \\
EX & 16 & 59.18 & 1.54 & 6.19 & 0.502 & 0.564 \\
\hline
\end{tabular}

The results of skewness analysis were 0.794 $(0.448 / 0.564)$ and $0.890(0.502 / 0.564)$ for the control and experimental groups, respectively. Since both values fell within the range of -1.96 and +1.96 , it was decided that the distributions of scores in both groups were normal.

\subsection{Writing Pretest Results}

Next, a descriptive essay writing pretest was administered in order to determine the participants' writing ability before the treatment. Two raters scored the students' essays using the Cambridge ESOL common scale by giving them scores from 0 to 10 . The descriptive statistics of the writing pretest are reported in Table 2.

Table 2. Descriptive statistics of the writing pretest of both groups

\begin{tabular}{|lllccc|c|}
\hline & & \multicolumn{3}{c}{ Std } & \multicolumn{3}{c|}{ Skewness } \\
& $\mathrm{N}$ & Mean & Error. Mean & SD & Statistic & Std. Error \\
\hline C & 16 & 4.50 & 0.28 & 1.14 & -0.193 & 0.564 \\
EX & 16 & 4.34 & 0.36 & 1.45 & -0.652 & 0.564 \\
\hline
\end{tabular}

The Pearson Product-Moment inter-rater reliabilities of the writing pretests were 0.881 and 0.889 for the control and experimental groups, respectively, which were satisfactory. Hence, the total writing score of each participant was computed through averaging the two raters' scores.

Table 3. Independent samples t-test for the writing pretest of both groups

\begin{tabular}{|c|c|c|c|c|c|}
\hline & \multicolumn{2}{|c|}{ Levene's test } & \multicolumn{3}{c|}{$\mathrm{t}$-test } \\
\cline { 2 - 6 } & $\mathrm{F}$ & Sig. & $\mathrm{t}$ & $\mathrm{df}$ & $\begin{array}{c}\text { Sig. } \\
\text { (2-tailed) }\end{array}$ \\
\hline $\begin{array}{c}\text { Equal } \\
\text { variances }\end{array}$ & 2.23 & .145 & -.33 & 30 & .738 \\
\hline $\begin{array}{c}\text { Not equal } \\
\text { variances }\end{array}$ & & & -.33 & 28.30 & .738 \\
\hline
\end{tabular}

The results of skewness analysis were 0.34 ($0.193 /-0.564)$ and $-0.1 .15(-0.652 / 0.564)$ for the control and the experimental groups, respectively, which testified to the normality of score distributions within each group. To verify the equality of the 
variances of the two groups, a Levene's test was performed before proceeding with the experiment. With $F=2.234, \quad P=0.145$ (two-tailed), it was concluded that the two groups enjoyed homogenous variances (see Table 3 ).

Further, a t-test was carried out to investigate the differences between the means of the two groups. With $\mathrm{t}(30)=-.338, P=0.738$ (two tailed), it was decided that there was not a statistically significant difference at $P>0.05$ level between the means of the two groups on the pretest (Table 3). Therefore, the two groups were homogenous regarding their writing skill and belonged to the same population prior to the study. Accordingly, any probable difference between the two groups at the end of the experiment could be attributed to the effects of the treatment.

\subsection{Post-test Results}

At the end of the 16-session treatment period, a descriptive essay writing post-test was administered to the participants in both groups to investigate the changes in their writing ability. The scripts were scored analytically by the two raters. The correlation coefficients between the two sets of scores were 0.765 and 0.796 for the experimental and control groups, respectively, indicting an acceptable level of agreement between the judges' ratings on the posttest.

The total score of each participant was calculated through averaging the two scores given by the raters. The descriptive statistics of the posttest are presented in Table 4. The mean of the experimental group $(M=6.75, S D=1.10)$ was larger than that of the control group $(M=4.90, S D=1.35)$. However, further statistical analyses were required to see whether the difference was statistically significant.

Table 4. Descriptive statistics of the writing posttest of both groups

\begin{tabular}{|lccccc|c|}
\hline & & & Std & \multicolumn{3}{c|}{ Skewness } \\
& N & Mean & Error. Mean & SD & Statistic & Std. Error \\
\hline C & 16 & 4.90 & 0.33 & 1.35 & 0.233 & 0.564 \\
EX & 16 & 6.75 & 0.27 & 1.10 & -0.964 & 0.564 \\
\hline
\end{tabular}

The results of skewness analysis, 0.413 $(0.233 / 0.564)$ and $-01.70(-0.964 / 0.564)$, revealed that the assumption of normality was observed in the distribution of the writing post-test scores of both groups. Next, a Levene's test and an independent samples $t$-test were conducted to compare the variances and the means of the two groups' post-test scores (see Table 5).
Table5. Independent samples t-test for the writing post-test of both groups

\begin{tabular}{|c|c|c|c|c|c|}
\hline & \multicolumn{2}{|c|}{ Levene's test } & \multicolumn{3}{|c|}{$\mathrm{t}$-test } \\
\cline { 2 - 6 } & $\mathrm{F}$ & Sig. & $\mathrm{T}$ & $\mathrm{df}$ & $\begin{array}{c}\text { Sig. } \\
\text { (2-tailed) }\end{array}$ \\
\hline $\begin{array}{c}\text { Equal } \\
\text { variances }\end{array}$ & .866 & .360 & 4.21 & 30 & .000 \\
\hline $\begin{array}{c}\text { Not equal } \\
\text { variances }\end{array}$ & & & 4.21 & 28.8 & .000 \\
\hline
\end{tabular}

With $\mathrm{F}=.866, p=.360$ (two-tailed), it was decided that the variances of the two groups were equal on the post-test. Moreover, with t $(30)=4.21, P=.000$ (two-tailed), it was concluded that there was a significant difference between the means of the experimental group and the control group. In other words, the experimental group (creative tasks group) had significantly outperformed the control group (communicative tasks group) in terms of L2 writing.

\section{Results and Discussion}

The results of this study demonstrated that the employment of creative writing tasks as opposed to communicative tasks can promote FLLs' composing abilities and extend the boundaries of their use of novel vocabulary and grammatical structures in their written products. There were some reasons for these findings.

The creative writing tasks used in this study were of different kinds: writing simple name poems, short stories, TV adverts, acrostic poems, newspaper articles and headlines, and travel guide brochures. Having formal and semantic constraints was a common feature of all the creative tasks used in this study. For example, one of the creative tasks employed in the experimental group of this study was writing a name poem.

Name poems have highly explicit rules and impose two constraints. Students must start every line with the letter of their friend's first name (formal constraint) and the whole poem must relate to the keyword (semantic constraint). These constraints seem to have stimulated creative language use and forced students in the experimental group to explore, expand, and transform language both at lexical and syntactic levels. Writing name poems provided more opportunities for the emergence of complex syntax and creative language use.

Based on the Cambridge English assessment scale used to rate the essays in this study, the students' posttest essays in the experimental group showed significant improvement. The results 
demonstrated that the members of the experimental group used a wider range of vocabulary in their utterances and a wider range of simple and complex grammatical forms in their essays. Combining formal constraints with semantic constraints forced learners to search for less accessible words and phrases, broaden their existing vocabulary, and construct complex structures. On the contrary, lack of formal and semantic constraints, as observed in communicative tasks, like reordering the words of a line, using a given sentence structure to write new patterns, or to express in written form what they had seen in a picture or had been given as known information let the learner's linguistic system in the control group fall into the state of using known utterances and matured structures rather than exploring and transforming their linguistic world.

The formal and semantic constraints observed in name poems and other creative tasks of this research seemed to create a kind of transmission phase. They required the students in the experimental group to develop new compositional strategies and syntactic structures and combine known familiar utterances in unfamiliar ways in order to construct new meanings. Such a transmission phase was missing in communicative tasks where learners in the control group could construct the new message through conveying known meaning. This lack of pressure to use the L2 for constructing unknown meaning produced a lack of desire to learn or invent complicated language. The students in the control group did not attempt to stretch and transform their L2 linguistic and conceptual worlds. There were more instances of applying known structures and utterances in different contexts rather than expanding them or introducing new structures to known utterances. A pre-fixed sentence structure was in fact employed to express known meaning, and sentence patterns and meanings remained relatively unmodified since the students continually used particular known sentence structures and utterances.

Another creative task of this study illustrated the playful use of language and manipulation of linguistic form and meaning for the purpose of writing a short story. The analysis of the data demonstrated the difference in the language used during playful and non-playful discourse processes. Learners were eagerly engaged in playful language which allowed and required them to experiment with new structures and lexical items that were not usual parts of the communicative tasks. Learners' utterances gave way to the emergence of a richer and more meaningful language. Even the grammatical errors seen in their production suggested that they were taking some risks with the target language. Nevertheless, engaging in the communicative tasks, where the learners in the control group were asked to rearrange the elements of a sentence, find the mistakes in a passage, or rewrite a new sentence by inserting a new word, seemed to encourage less complex constructions in order to ensure a conventional and perhaps more error-free performance.

Furthermore, the findings of the study highlighted various perspectives on the key differences between a communicative task and a creative task. In a communicative task, the focus is on known meaning or meaning known to self, whereas in a creative task, the focus is on constructing unknown meaning or meaning new to self. In a communicative task, teachers establish an information gap between students to encourage them to use the language to communicate with each other. In a creative task, promoting a creative desire to explore and transform language through adding or discovering new constraints is as important as communicating known meaning. Through establishing a familiar experience, communicative tasks help students to relate a topic to their own lives. On the other hand, a creative task makes familiar topics unfamiliar to help students to broaden their language and be more creative.

\section{Conclusions}

Obviously, this study did not intend to criticize communicative language teaching or advocate its exclusion. Rather, it recommends that communicative language teaching should broaden its scope to include a wider range of activities including playful or creative ones. Communicative and conventional tasks still have an important place in language curriculum when it comes to increasing language fluency and accuracy. Since language learners can benefit from both creative tasks and communicative tasks, ELT classrooms should provide room for communication as well as creativity, and it is true that creative tasks and communicative tasks can complement each other. Conditions should be set up in EFL classrooms to establish a creative desire among learners to use language to express new meaning. Researchers, teachers, and text book developers should experiment with a variety of innovative writing tasks and activities with many design features of creative tasks to make EFL classrooms more attractive.

Today, writing is no more considered to be an individual activity which should be done solely as an assignment. On the contrary, it is a cognitive process needing nurturing and attention in the social context of classroom. Therefore, the implementation of the concept of creativity and innovation in education and specifically in language learning/teaching needs a clear perspective and close collaboration of the researchers, teachers, and decision makers in educational centers to adjust the educational environment to the necessities of the society in order 
to promote creativity. Curriculum developers should re-examine the writing materials currently used in teaching the writing skill and the instructional methods in use. What remains the most important social instrument to foster creativity of EFL students on a large scale is a refined school with trained teachers and reformed textbooks.

\section{References}

[1] Chomsky, N., Aspects of the theory of syntax, MIT Press, Cambridge, Massachusetts, 1965.

[2] Tin, T.B., "Towards creativity in ELT: the need to say something new", ELT Journal, 67(4), 2013, 385-397.

[3] Pomerantz, A., and Bell, N., "Learning to Play, playing to learn: FL learners multicompetent language users", Applied Linguistics, 28(4), 2007, 556-578.

[4] Cook, G., Language play, language learning, Oxford University Press, Oxford, 2000.

[5] Tarone, E., Getting serious about language play: Language play, interlanguage variation and second language acquisition. In B. Swierzbin, F. Morris, M. E. Anderson, C. Klee, and E. Tarone (Eds), Social and Cognitive Factors in Second Language Acquisition: Selected proceedings of the 1999 second language research forum. Somerville, MA: Cascadilla Press (pp. 3154), 2000.

[6] Leung, A. K., Maddux, W. W., Galinsky, A. D., and Chiu, C., "Multicultural experience enhances creativity: the when and how", American Psychologist, 63(3), 2008, 169-81.

[7] Kim, Y.-H., and Kellogg, D., Rules out of roles: "Differences in play language and their developmental significance", Applied Linguistics, 28(1), 2007, 25-45.

[8] Tin, T. B., "Language creativity and co-emergence of form and meaning in creative writing tasks", Applied Linguistics, 32(2), 2011, 215-35.

[9] Lutzker, P., Practicing creative writing in high school foreign language classes. In Maley, A and Peachey, N(Ed), Creativity in English language classroom. British Council, UK, 2015.

[10] Chase, B, J., An analysis of the argumentative writing skills of academically underprepared college students. Doctor of Philosophy Thesis, Columbia University, 2011.

[11] K.I., Secondary English Teacher's Handbook Nairobi, Kenya Institute of Education, 2006.

[12] Maley, A., Creative writing/reading. In Mukundan, J (Ed), Creative Writing in EFL/ESL classrooms II. Pearson Longman, Malaysia, 2006.

[13] Joyce, C. K., The blank page: effects of constraint on creativity. (Unpublished doctoral dissertation). University of California, Berkeley, USA, 2009.
[14] Stokes, P. D., Creativity from constraints: The psychology of breakthrough, Springer Publishing, New York, NY, 2006.

[15] Tin, T. B., Manara, Ch., and Ragawanti, D.T., "Views on creativity from an Indonesian perspective". ELT Journal, 64(1), 2010, 75-84.

[16] Tarone, E., "Frequency effects, noticing and creativity (factors in a variationist interlanguage framework)". Studies in Second Language Acquisition, 24(2), 2002, 28796.

[17] Runco, M. A., "Creativity". Annual Review of Psychology, 55, 2004, 657-87.

[18] Dörnyei, Z., The psychology of the language learner: Individual differences in second language acquisition, Lawrence Erlbaum, London, 2005.

[19] Boden, M. A., Creativity and knowledge. In A. Craft, B. Jeffrey, \& M. Leibling (Eds.), Creativity in education. London: Continuum, 2001.

[20] Finke, R. A., Ward, T. B., \& Smith, S. M., Creative cognition: Theory, research and applications. Cambridge, MA: MIT Press, 1992. 